Research Article

\title{
Shear Properties of Cemented Paste Backfill under Low Confining Stress
}

\author{
Andrew N. Pan $\mathbb{D}^{1},{ }^{1}$ Murray W. F. Grabinsky ${ }^{D},{ }^{1}$ and Lijie Guo $\mathbb{C D}^{1,2}$ \\ ${ }^{1}$ Department of Civil \& Mineral Engineering, University of Toronto, Toronto, Ontario M5S 1A4, Canada \\ ${ }^{2}$ Beijing General Research Institute of Mining and Metallurgy, Beijing 100160, China \\ Correspondence should be addressed to Andrew N. Pan; andrew.pan@mail.utoronto.ca
}

Received 29 June 2021; Accepted 15 September 2021; Published 14 October 2021

Academic Editor: Zhi Cheng Tang

Copyright $\odot 2021$ Andrew N. Pan et al. This is an open access article distributed under the Creative Commons Attribution License, which permits unrestricted use, distribution, and reproduction in any medium, provided the original work is properly cited.

Cemented paste backfill (CPB) plays an important role in the mining industry due to safety, cost efficiency, and environmental benefits. Studies on CPB have improved the design and application of paste backfill in underground mines. Direct shear is one of the most fundamental parameters for assessing backfill strength. This study harnesses direct shear tests to explore the low confining stress behavior of CPB. We perform all the tests in a standard apparatus on the combination of three binder contents of $4.2 \%, 6.9 \%$, and $9.7 \% \mathrm{CPB}$ with four curing times of 3, 7, 14, and 28 days, respectively. The applied confining stress levels vary in a range according to the in situ regime. Results are presented by strength envelope, stress-strain property, and shear strength with curing time and binder content. The data suggest that the shear strength follows the Mohr-Coulomb envelope in which the shear strength and behavior are time and binder content dependent. In addition, the results show that shear strength is strongly related to the binder content than the curing time, namely, the higher the degree of binder hydration, the higher the cementation binding force between CPBs.

\section{Introduction}

Cemented paste backfill (CPB) is a composite backfill technique used as a regional ground support. Composite backfilling is classified into three categories, rock fill, hydraulic fill, and paste fill, based on their particle sizes and water contents [1]. Rock fill is predominantly composed of crushed rocks. Hydraulic fill and paste fill are characterized by their finer particles and differentiated by their postdeposition properties [2]. In addition, the paste fill is characterized by a lower water content, while the hydraulic fill is characterized by a higher water content, which requires a large amount of postprocessing $[1,2]$.

The use of CPB is currently practical in many modern mines throughout the world, particularly in Canada, China, and Australia. CPB plays an increasingly important role due to safety, cost efficiency, and environmental benefits. CPB is a homogenous mixture obtained by mixing tailings with water and hydraulic binder. Its designs are based on regional ground conditions, tailing behaviors, and operational requirements [3-5]. $\mathrm{CPB}$ consists of $70 \%$ to $85 \%$ fine particles by weight and incorporates $2 \%$ to $9 \%$ binder, generally Portland cement and possibly fly ash or ground blast furnace slag $[3,6,7]$. $\mathrm{CPB}$ is placed in the mined-out stope to form a selfsupporting ground structure. The stability of the $\mathrm{CPB}$ structure is governed by its mechanical properties under low confining stresses $[8,9]$.

Historically, one of the most fundamental designs for exposed paste backfill was proposed by Mitchell et al. in 1982, which is commonly referred to as "Mitchell's Analytical Solution" (Figure 1). In this model, backfills were conducted with sidewall exposure [8]. The observed failure was interpreted by a wedge failure mechanism based on the unconfined compressive strength (UCS) [8]:

$$
\sigma_{n}=\frac{\gamma H}{(1+H / L)},
$$

where $\sigma_{n}$ is the UCS, $\gamma$ is the unit weight, $H$ is the exposed face height, and $L$ is the exposed side length. 
Mitchell et al. [8] assumed that the low confining strength followed a constant strength envelope. Their assumption satisfied the stability requirement of the early arching solutions. While their assumption was acceptable by the early approaches, modern design is more analytical driven which requires a more rigorous approach. Veenstra [10] demonstrated that the strength properties of CPB followed a continuous strength envelope, and the shear resistance increased with the confining stress. As pointed by Veenstra [10], the early approaches were inadequate. Therefore, we need to investigate the geomechanics of the low confining stress behavior of $\mathrm{CPB}$.

The shear response of CPB has been the focus of several research projects including the shear response of backfillbackfill interfaces [11], backfill-rock interfaces [12], and simulated tailings [13]. Direct shear is a rapid method to determine the strength properties through a predefined shear plane. It provides an effective approach to determine shear strength [8]. The backfill engineering designs depend on the mechanical properties of various types of CPB for ongoing mining, which are often done by laboratory studies $[3,14]$. Although the results of previous studies contribute to the understanding of the phenomena, it remains that more investigation is needed for understanding the shear property of CPB. The results have important implications including allowing mine engineers to design and optimize the filling strategy, binder content, and curing time of $\mathrm{CPB}$.

In consideration of the facts that are mentioned above, we have initiated an intensive research project at the University of Toronto to gain a comprehensive understanding of low confining stress properties of CPB. Although the low confining stress on rock mechanics is not a major concern, previous research has shown that low confining stress has a significant impact on the stability of CPB structures due to the arching effect $[12,15]$. In the filled stopes, the vertical stress of CPB is transferred horizontally to the adjacent rock walls which leads to the arching effect $[8,12,15]$. The arching effect reduces the vertical load in CPB structures, resulting in a stress regime which is significantly less than the overburden weight. Studies conducted by Grabinsky [3] and Thompson et al. [16] have shown that the maximum in situ stress of $\mathrm{CPB}$ ranges from 150 to $250 \mathrm{kPa}$. In this study, $\mathrm{CPB}$ low confining stress designs are therefore based on the operation requirements and regional ground conditions which reflect the current operation at the mines. The early strength governs the integrity of the barricade, and the cured strength controls the stability of the CPB structure $[6,17]$. Typically, the subsequent openings commence 28 days following the primary stope [1]. The geomechanical properties of CPB serve as an integral component of the mine design. The maturation and the in situ characteristics of paste backfill are the subjects of industrial interest and academic research. Therefore, the objectives of our research are as follows:

(1) Evaluate the nature of early strength and the cured strength of $\mathrm{CPB}$

(2) Evaluate the strength property of $\mathrm{CPB}$ with the binder content and curing time
(3) Evaluate the stress and strain properties of $\mathrm{CPB}$

\section{Materials and Methods}

2.1. Mill Tailing Samples. The tailing samples were collected from Barrick's Williams Operation in the Hemlo mining camp, Ontario, Canada. The Williams mine is located in Northwest Ontario, approximately $35 \mathrm{~km}$ west of the township Marathon. The ores are primarily amphibolitefacies Archean load gold deposits [18]. The deposits were extracted with a mixture of long hole stope and Alimak stope and subsequently backfilled with CPB. The ore is milled to paste consistency with more than $45 \%$ passing $0.020 \mathrm{~mm}$ as shown in Figure 2 [19]. The tailing stream consists of silica, quartz, feldspar, and plagioclase. Table 1 shows the chemical composition of the tailing, Table 2 shows the chemical compositions of the binder, and Figure 2 shows the grain size distribution of tailings [19]. Sulfides in the tailings can be oxidized which alters the material's initial grey to orange color when exposed to oxygen [9].

The previous studies showed that the mechanical properties of CPB depend on its physical and chemical characteristics of the binder type, particle size, water content, and tailings' mineralogy $[3,10,14,16,19,20]$. These mechanical properties vary significantly with the binder content and curing time. Therefore, in this study, normal Portland cement is used as the basic binding agent, reflecting current practice at Williams Mine. The $4.2 \%$ and $6.9 \%$ binder contents are used to simulate typical mining practice, and the $9.7 \%$ binder content is the upper bound and reflects the maximum concentrations used for critical applications such as undercut structures. The samples are prepared with $28 \%$ mine water content based on a recent field study which showed the mine water content ranged from $26.5 \%$ to $29.6 \%$ in Williams Mine [3].

2.2. Equipment. The experiments were conducted with a constant strain direct shear apparatus by the Engineering Laboratory Equipment Co., in accordance with ASTM Standard D3080 [21]. The samples were fitted into a shear box and sheared at a constant strain rate with the electric motor as shown in Figure 3. The electric motor sheared the sample through the relative displacement of 2 halves of shear boxes, the upper box is fixed, and the lower box is movable.

The shear box is connected to a digital data acquisition system. The linear displacement is recorded by the linear variable differential transformer (LVDT) placed against the sample enclosure. The vertical dilation is tracked by the LVDT placed perpendicular against the enclosure. The shear resistance is determined by a load cell in the direction of travel. The LVDTs and load cell are connected to a data acquisition system, and the values are tracked with a frequency of $10 \mathrm{~Hz}$. The vertical loading rate is determined by the time to achieve $50 \%$ consolidation, which is incremented in $45 \mathrm{~s}$ to alleviate the excess pore pressure. The sample is sheared at a constant rate of $1 \%$ per minute.

The samples are cast into the $60 \mathrm{~mm} \times 60 \mathrm{~mm} \times 50 \mathrm{~mm}$ blocks by a 4-part split mold based on Veenstra's experiments [10]. The 4-part split mold consists of 2 side enclosures with sill inserts and 2 base enclosures with O-ring as 


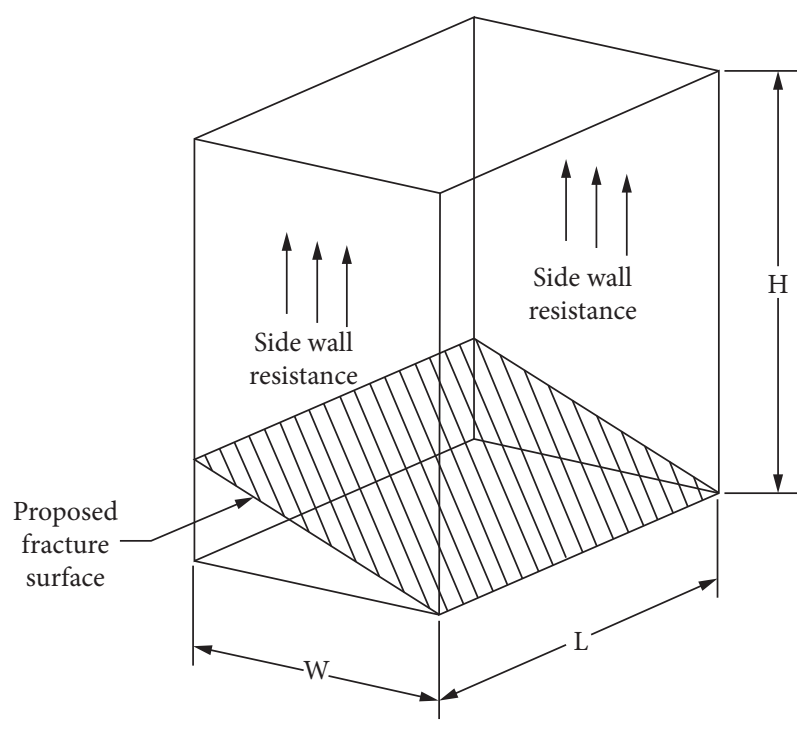

Figure 1: Mitchell's wedge mechanism.

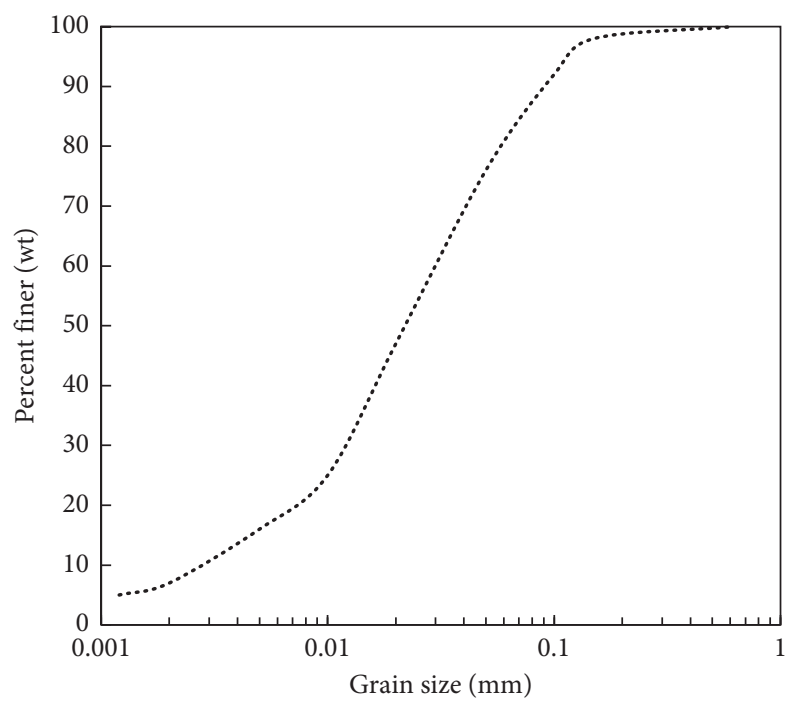

FIGURE 2: Tailing grain size distribution.

shown in Figure 4. The preliminary tests showed that the steel mold has a significant amount of rust built up which led to the concern of sample degradation; therefore, the modified mold is made of polyethylene terephthalate (PETG) plastic in the main experiment. The sample enclosure is filled with water to reduce the effect of suction during the test.

2.3. Experimental Protocol. The stress ranges are determined from field research by Grabinsky [3] (Figure 5). The study showed the maximum in situ stress ranged from 150 to $200 \mathrm{kPa}$. Therefore, a total of 6 stress intervals of $1 \mathrm{kPa}, 20 \mathrm{kPa}, 40 \mathrm{kPa}$, $80 \mathrm{kPa}, 130 \mathrm{kPa}$, and $210 \mathrm{kPa}$ confining stress are selected for this study which corresponded to the in situ stress condition.

In this study, a total of 72 trials were conducted with the combination of 3 binder contents of $4.2 \%, 6.9 \%$, and $9.7 \%$ and 4 curing times of $3,7,14$, and 28 days, and the configurations are shown in Table 3.

\section{Results and Discussion}

In developing the experimental protocols, a series of preliminary experiments were conducted to determine the range of factors, including confining stress, binder content, curing time, and load rate. Sample results are plotted in Figure 6 which show that increased cement content results in decreased compressibility. The trends are observed in all samples of $4.2 \%, 6.9 \%$, and $9.7 \% \mathrm{CPB}$, along with the rationale for the conditions selected for subsequent experiments.

In the main experiments, direct shear results are presented by three types of analysis: strength envelope, stressstrain property, and shear strength with curing time and binder contents. The combination of three binder contents of $4.2 \%, 6.9 \%$, and $9.7 \%$ and four curing times of $3,7,14$, and 28 days is presented and compared in each analysis.

3.1. Strength Envelope. Figure 7 shows the effect of binder contents and curing time on the strength envelopes of CPB. The results indicate that shear resistance increases linearly with applied normal stresses with the coefficient of determination $R^{2}$ ranging from 0.95 to 0.99 . It can be seen that regardless of the curing time and binder contents, the peak strength follows the Mohr-Coulomb envelope.

$$
\tau_{p}=\sigma_{n} \tan \phi_{p}+c,
$$

where $\tau_{p}$ is the peak shear stress, $\sigma_{n}$ is the normal stress, $\phi_{p}$ is the angle of frictional resistance, and $c$ is the cohesion. The peak shear strength $\tau_{p}$ is determined by the cohesion and the angle of frictional resistance. Cohesion is the shear strength or the cementation that binds CPB together. Results show that cohesion increases from early 3 to advanced 28 days of curing time and from $4.2 \%$ to $9.7 \%$ of binder contents, which can be attributed to the fact that longer curing time and a higher cementation binding force resulted from a higher degree of binder hydration. This finding is significant since it means that shear strength properties depend on the binder content and curing time. By contrast, the residual shear strength $\tau_{r}$

$$
\tau_{r}=\sigma_{n} \tan \phi_{r},
$$

is governed by the angle of frictional resistance alone. It can be seen from the data that neither the peak nor the residual friction angles in this study show a consistent trend with increasing binder content or increasing curing time as shown in Figure 7. This result is consistent with studies on shear strength between CPB and rock [11].

3.2. Stress-Strain Property. The stress-strain property of $4.2 \%, 6.9 \%$, and $9.7 \%$ binder contents at $3,7,14$, and 28 days of curing time is presented in Figures 8-10 for comparison. As expected, the peak stress increases with the confining stress. The typical stress-strain curves follow three stages: (a) the initial linear-elastic behavior, (b) postyield behavior from around $0.5 \%$ onward, and (c) postfracture behavior from around $1 \%$ strain onward. 
TABLE 1: Tailing mineralogy composition.

\begin{tabular}{lcccccccc}
\hline Composition & $\mathrm{CaO}$ & $\mathrm{SiO}_{2}$ & $\mathrm{SO}_{3}$ & $\mathrm{Al}_{2} \mathrm{O}_{3}$ & $\mathrm{MgO}$ & $\mathrm{Fe}_{2} \mathrm{O}_{3}$ & $\mathrm{~K}_{2} \mathrm{O}$ & $\mathrm{Na}_{2} \mathrm{O}$ \\
\hline Content (wt.\%) & 64.2 & 20.0 & 4.1 & 3.9 & 3.1 & 3.0 & 0.5 & 0.2 \\
\hline
\end{tabular}

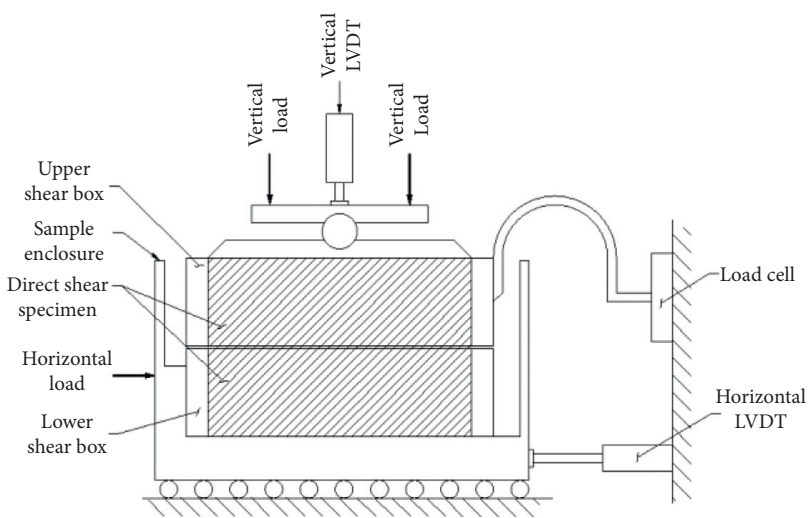

(a)

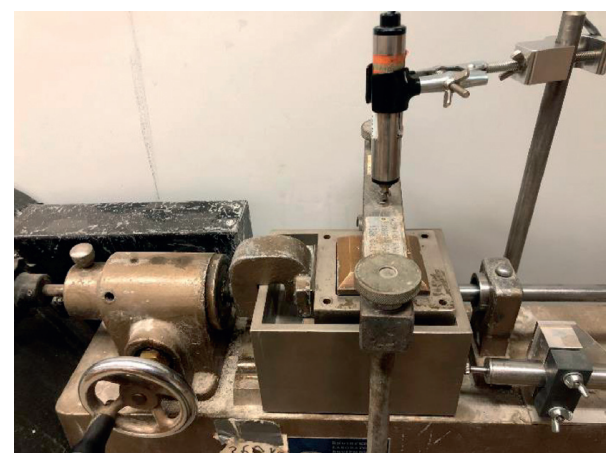

(b)

Figure 3: Direct shear apparatus. (a) Schematic of the direct shear apparatus. (b) Lab testing apparatus.

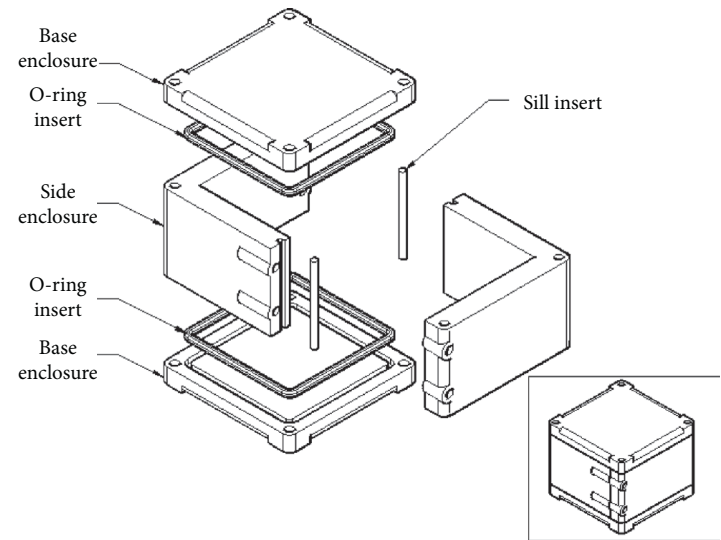

Figure 4: The 4-part spilt sample enclosure.

Figure 8 shows that, under low binder contents of $4.2 \%$ $\mathrm{CPB}$, the shear stress at levels $130 \mathrm{kPa}$ and $210 \mathrm{kPa}$ gradually increased with strain until it reached the maximum. In the case of the high stress following the failure, the confining stress led to the remolding of tailing particles resulting in a more compact state. The result is consistent with studies conducted by Nasir and Fall [12] that the shear stress exhibits postfailure strain hardening. By comparison, the shear stress at a lower level $(\leq 40 \mathrm{kPa})$ exhibits postfailure strain softening resulting in a less compact state; while stress $=80 \mathrm{kPa}$, the stress-strain curve showed elastic perfectly plastic behavior with nearly perfect plateau because residual shear conditions were achieved.

By contrast, the high binder content in Figure 10 shows the shear stress of $9.7 \% \mathrm{CPB}$ increases with shear strain until it reaches the peak stress. According to Nasir and Fall [12], this behavior can be attributed to the breakage of cement bonds. After the peak, the shear stress decreases as the shear strain increases, attributed possibly to the mobilization of the full frictional resistance. As the shear strain continues to increase, the shear stress remains relatively constant (for stress $\leq 80 \mathrm{kPa}$ ) or slightly decreases (for stress $=130 \mathrm{kPa}$ and $210 \mathrm{kPa}$ ). This behavior can be explained by dilation [12]. It can be observed that a longer curing time leads to a greater peak, and the curves reach the highest stress in 28 days due to the hydration increase with the time. The peak stressstrain curve of CPB can be explained by the fact that high strength accumulates a large amount of energy which leads to a quick propagation of cracks in the failure zone. Subsequently, the stress decreased sharply. We can observe similar behaviors in Figure 9 for the binder content of $6.9 \% \mathrm{CPB}$ which are less obvious than those in Figure 10.

3.3. Shear Strength with Curing Time and Binder Content. Figure 11 shows the effect of curing time and binder contents on cohesion. The CPB strength property with time during early curing time from 3 to 28 days can be expressed by a power law: 


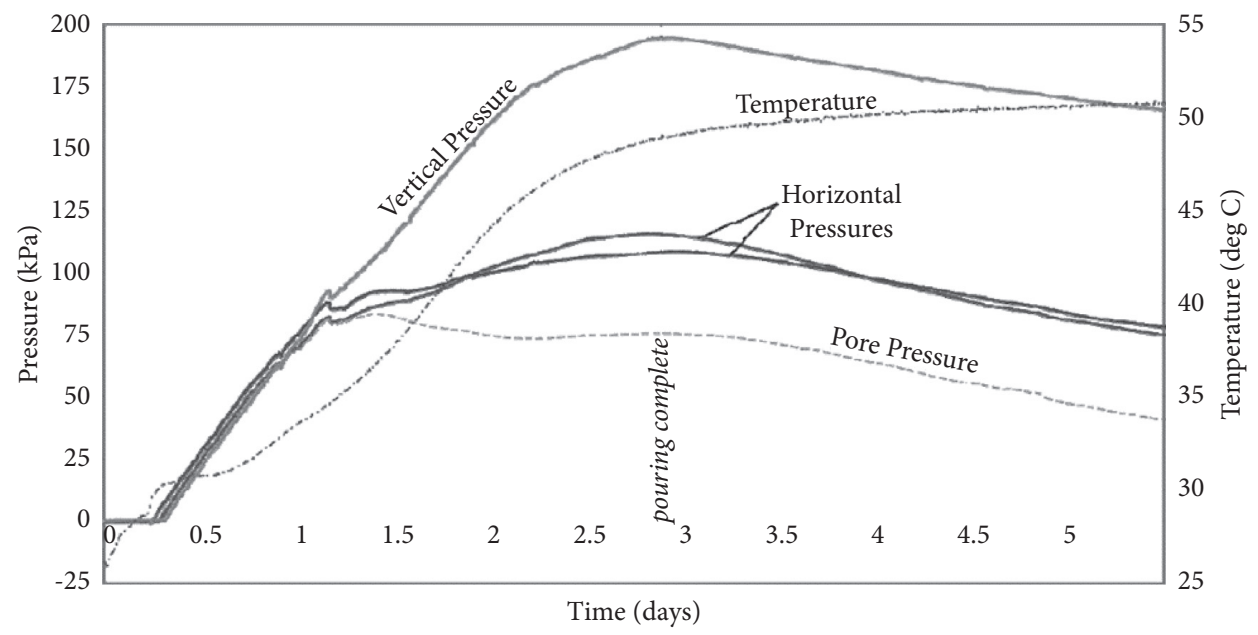

Figure 5: In situ stress regime [3].

TABLE 2: Binder chemical composition.

\begin{tabular}{lccccccccccc}
\hline Composition & $\mathrm{SiO}_{2}$ & $\mathrm{Al}_{2} \mathrm{O}_{3}$ & $\mathrm{CaO}$ & $\mathrm{MgO}$ & $\mathrm{K}_{2} \mathrm{O}$ & $\mathrm{Na}_{2} \mathrm{O}$ & $\mathrm{Fe}_{2} \mathrm{O}_{3}$ & $\mathrm{~S}$ & $\mathrm{TiO}_{2}$ & $\mathrm{P}_{2} \mathrm{O}_{5}$ & $\mathrm{Ba}$ \\
\hline Content (wt.\%) & 59.8 & 12.2 & 3.6 & 3.5 & 3.4 & 3.2 & 2.4 & 0.6 & 0.4 & 0.2 & 0.1 \\
\hline
\end{tabular}

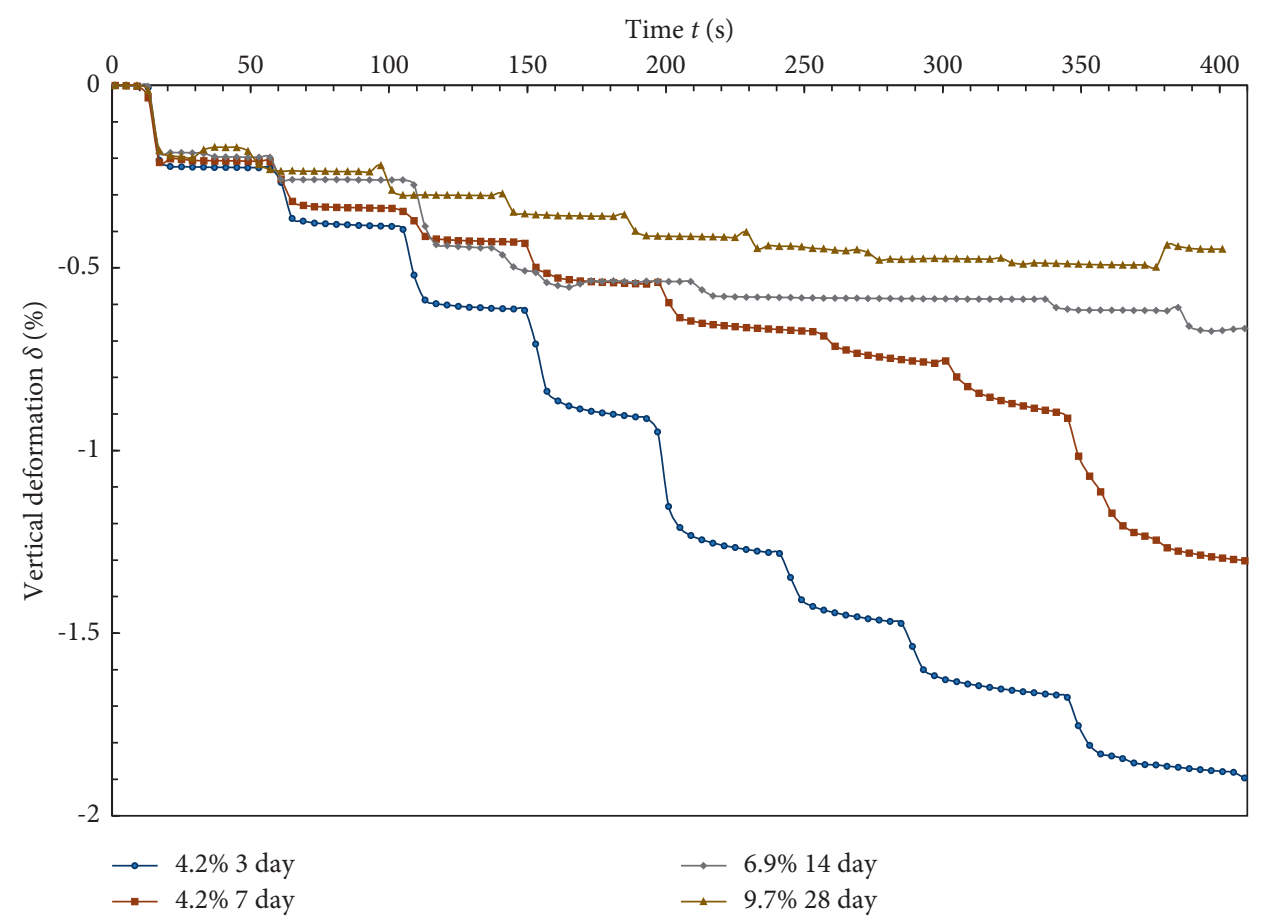

Figure 6: Vertical deformation with curing time and binder contents of CPB.

$$
c=a \cdot t^{b}
$$

where $c$ is the cohesion, $a$ is the constant coefficient, $t$ is the curing time in days, and $b$ is the power coefficient. The coefficient of determination $R^{2}$ value is over 0.95 for all $4.2 \%, 6.9 \%$, and $9.7 \%$ CPB. The strength increases with cohesion successively from 3 days to 28 days as shown in Figure 11(a). It indicates that the cohesion strength of $\mathrm{CPB}$ is time dependent. Indeed, as expected, as curing time increases, $\mathrm{CPB}$ tends to harden due to the more developed cement bonds. The results are more obvious in 9.7\% CPB than those of $4.2 \%$ and $6.9 \%$, which can be attributed to the progression of binder hydration with time.

Not only the curing time but also the binder contents significantly affect the strength behavior of $\mathrm{CPB}$. The $\mathrm{CPB}$ strength increase, expressed by cohesion, with binder contents can be observed in all the samples from $4.2 \%, 6.9 \%$, and $9.7 \% \mathrm{CPB}$ as shown in Figure 11(b), which can be characterized by the linear relationship. 
TABLE 3: Configuration of direct shear tests.

\begin{tabular}{lcccc}
\hline Binder content $B_{c}(\%)$ & Binder type & Curing time $t$ (days) & Stress interval $(\mathrm{kPa})$ & Number of samples \\
\hline 4.2 & $100 \%$ GPC & $3,7,14$, and 28 & $1,20,40,80,130,210$ & 24 \\
6.9 & $100 \%$ GPC & $3,7,14$, and 28 & $1,20,40,80,130,210$ & 24 \\
9.7 & $100 \%$ GPC & $3,7,14$, and 28 & $1,20,40,80,130,210$ & 24 \\
\hline
\end{tabular}
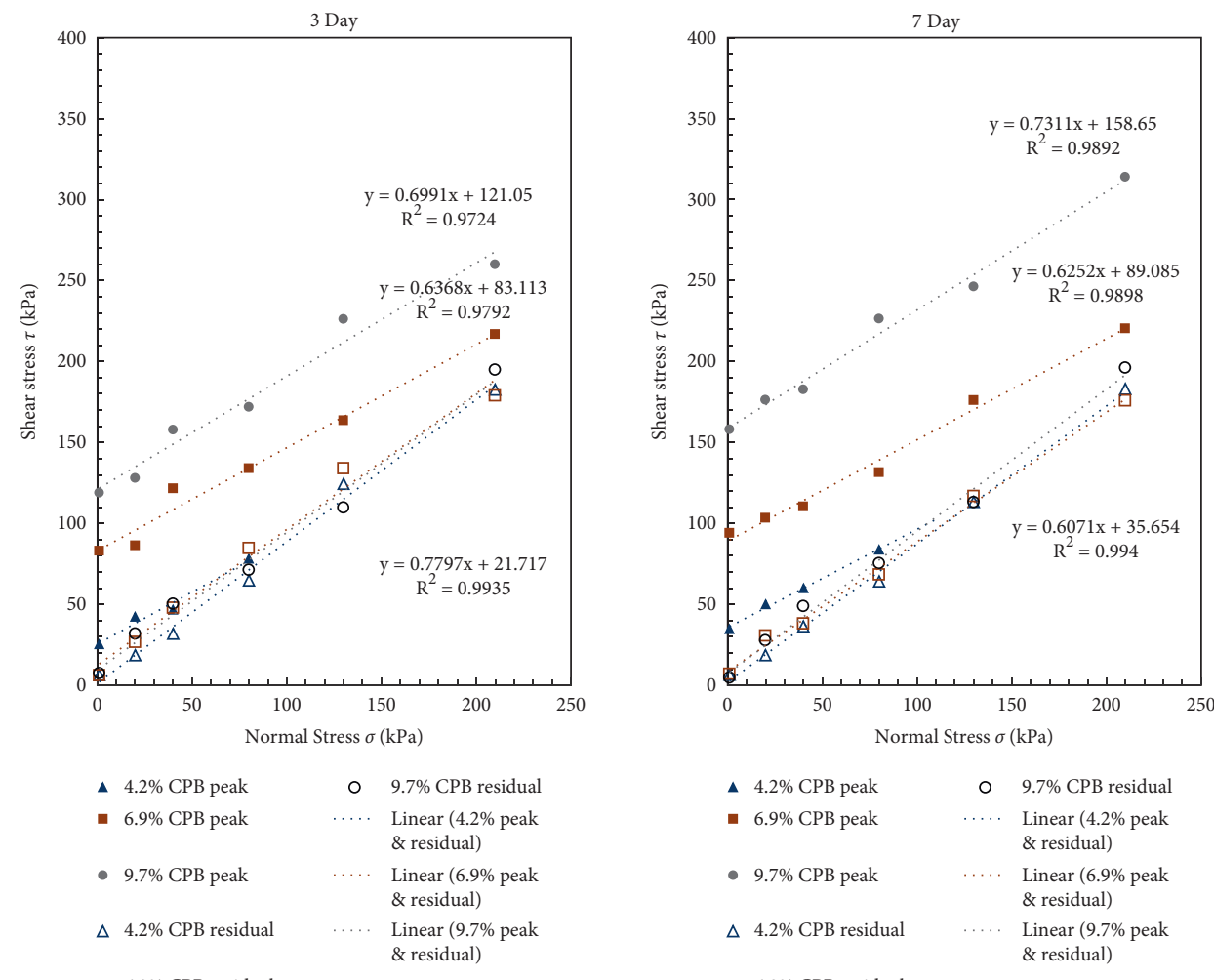
- $4.2 \% \mathrm{CPB}$ peak
○ $\quad 9.7 \% \mathrm{CPB}$ residual
- $6.9 \% \mathrm{CPB}$ peak
Linear (4.2\% peak
- $9.7 \%$ CPB peak \& residual)
- $9.7 \%$ CPB peak
Linear $(6.9 \%$ peak
$\Delta \quad 4.2 \% \mathrm{CPB}$ residual \& residual)
ㅁ $6.9 \% \mathrm{CPB}$ residual
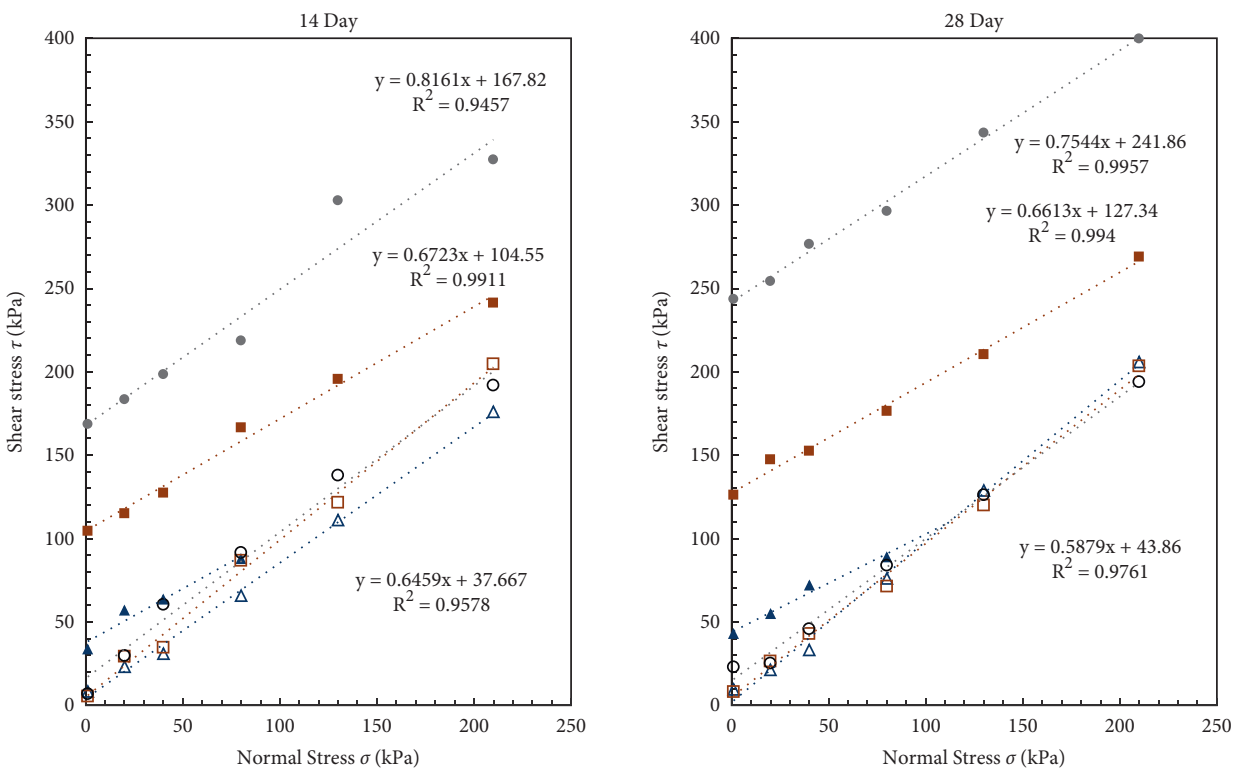
- $4.2 \% \mathrm{CPB}$ peak
- $\quad 9.7 \% \mathrm{CPB}$ residual
- $6.9 \%$ CPB peak \& residual)
- $9.7 \%$ CPB peak
Linear $(6.9 \%$ peak \& residual)
$\Delta \quad 4.2 \% \mathrm{CPB}$ residual
Linear $(9.7 \%$ peak
\& residual)

․ $6.9 \% \mathrm{CPB}$ residual

$$
\begin{aligned}
& \text { \ } 4.2 \% \mathrm{CPB} \text { peak } \quad \text { ○ } 9.7 \% \mathrm{CPB} \text { residual } \\
& \text { - } 6.9 \% \text { CPB peak } \quad \text { … Linear }(4.2 \% \text { peak } \\
& \text { \& residual) } \\
& \text { - } 9.7 \% \text { CPB peak } \quad \text { … } \quad \text { Linear }(6.9 \% \text { peak } \\
& \text { \& residual) } \\
& \Delta 4.2 \% \mathrm{CPB} \text { residual } \quad \ldots . . \quad \text { Linear }(9.7 \% \text { peak } \\
& \text { } 6.9 \% \mathrm{CPB} \text { residual }
\end{aligned}
$$

Figure 7: Binder content and curing time on strength envelope. 

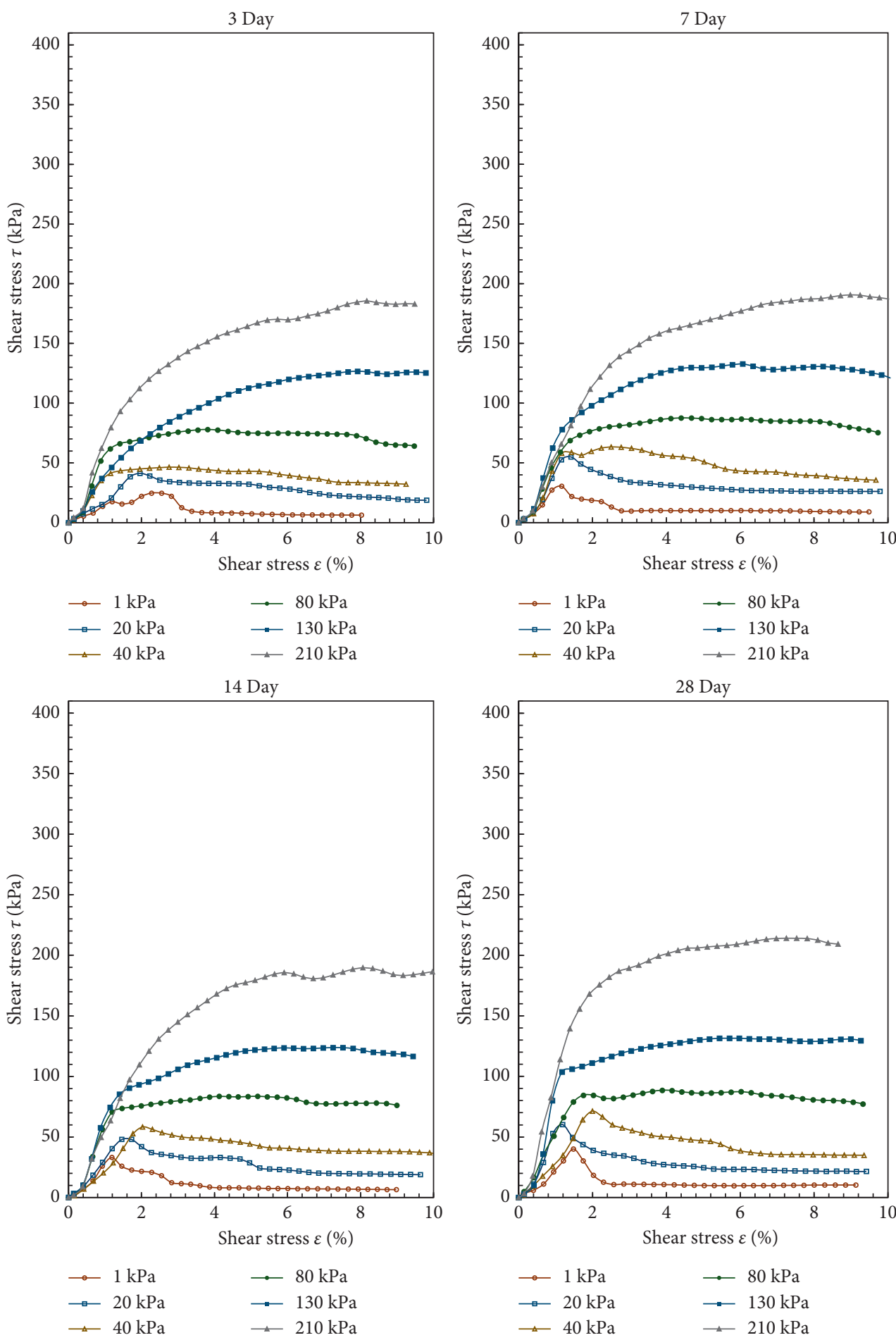

FIGURE 8: Shear stress-strain curve of $4.2 \%$ CPB.

$$
c=m \cdot B_{c}+b,
$$

where $c$ is the cohesion, $m$ is the constant coefficient, $B_{c}$ is the binder content, and $b$ is the constant. The trend of cohesion increase with the binder content is more obvious in 28-day curing time than that of 3,7 , and 14 days. This can be attributed to a longer curing time results in a higher degree of binder hydration. The result indicates that the higher binder content leads to the formation of more cement hydration products and thus to higher cohesive strength. 

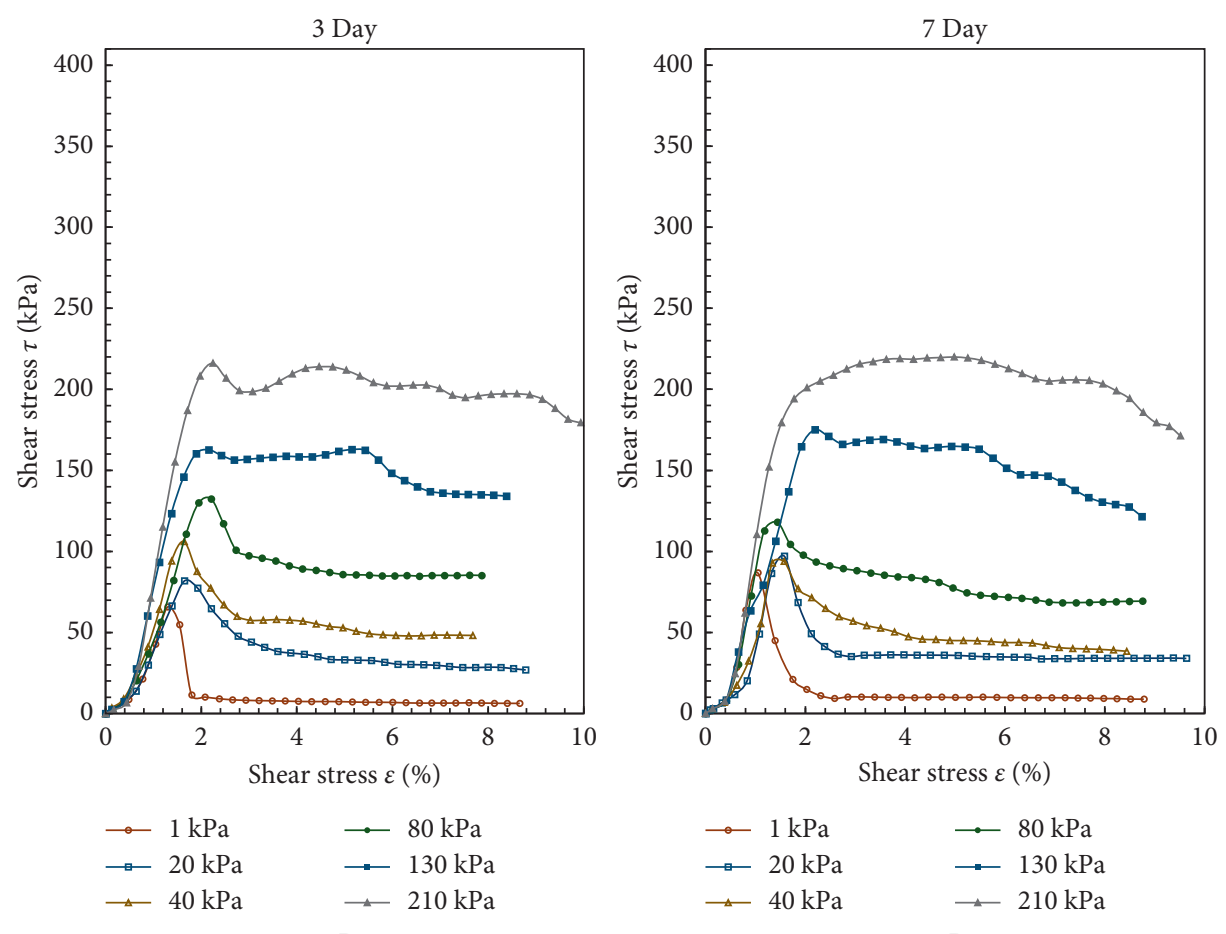

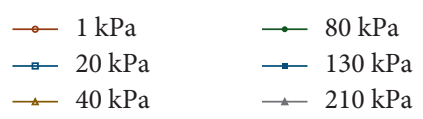
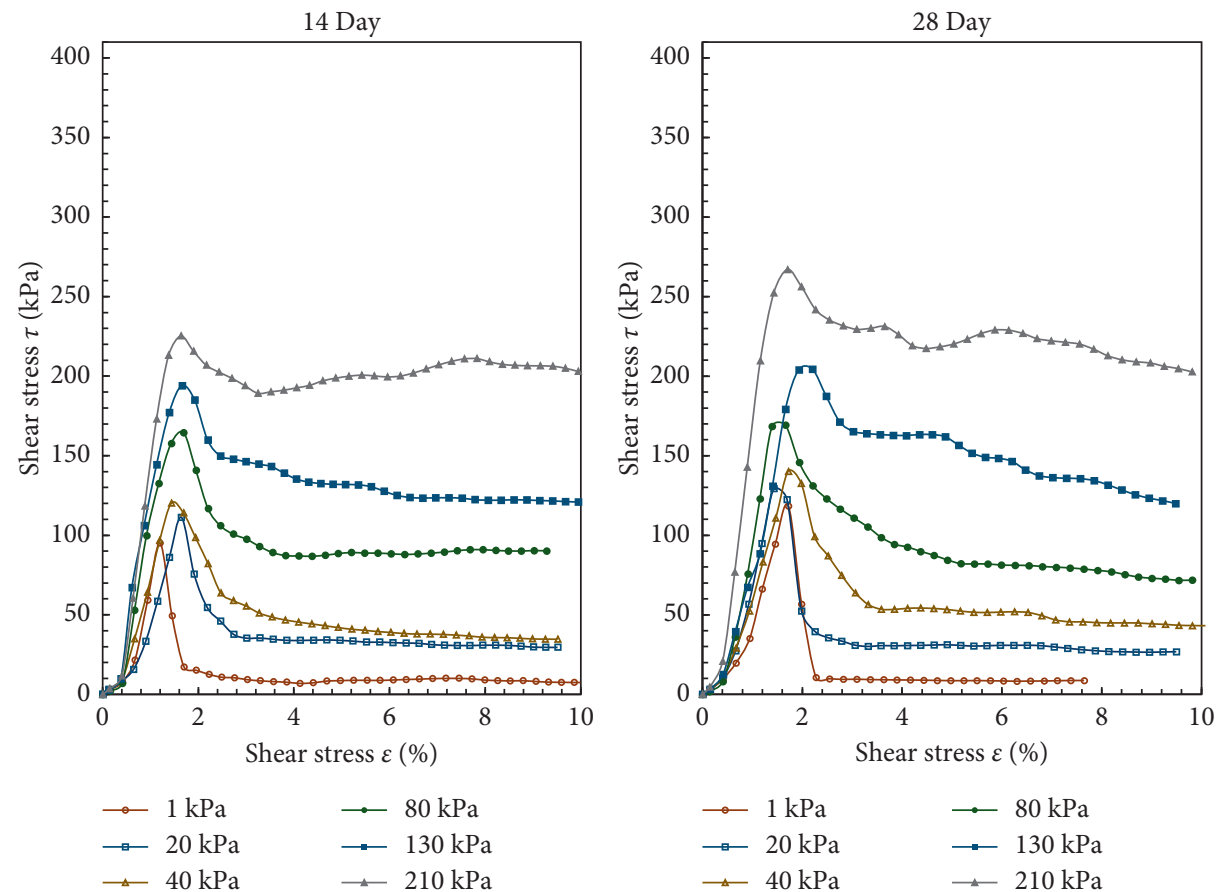

$$
\begin{aligned}
& \rightarrow 1 \mathrm{kPa} \\
& \rightarrow 80 \mathrm{kPa} \\
& \rightarrow-20 \mathrm{kPa} \\
& \longrightarrow 130 \mathrm{kPa} \\
& \triangle 40 \mathrm{kPa} \\
& \text { - } 210 \mathrm{kPa}
\end{aligned}
$$

FIgURE 9: Shear stress-strain curve of $6.9 \%$ CPB. 

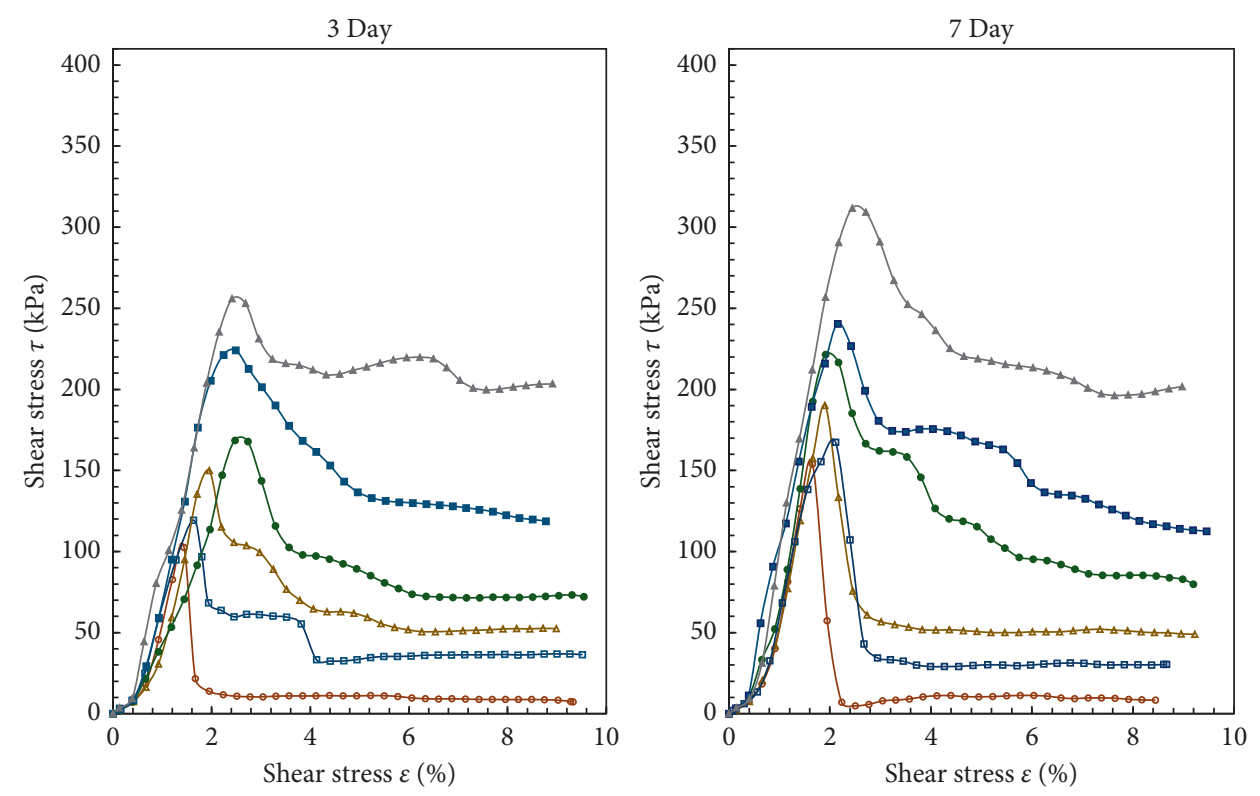

$$
\begin{aligned}
& \rightarrow 1 \mathrm{kPa} \\
& \rightarrow 80 \mathrm{kPa} \\
& \rightarrow 20 \mathrm{kPa} \\
& =130 \mathrm{kPa} \\
& \longrightarrow 40 \mathrm{kPa} \\
& \longrightarrow 210 \mathrm{kPa}
\end{aligned}
$$

$-1 \mathrm{kPa}$

$\rightarrow-80 \mathrm{kPa}$

$\rightarrow 20 \mathrm{kPa}$

$\rightarrow 130 \mathrm{kPa}$

$\rightarrow 40 \mathrm{kPa}$

$\longrightarrow 210 \mathrm{kPa}$
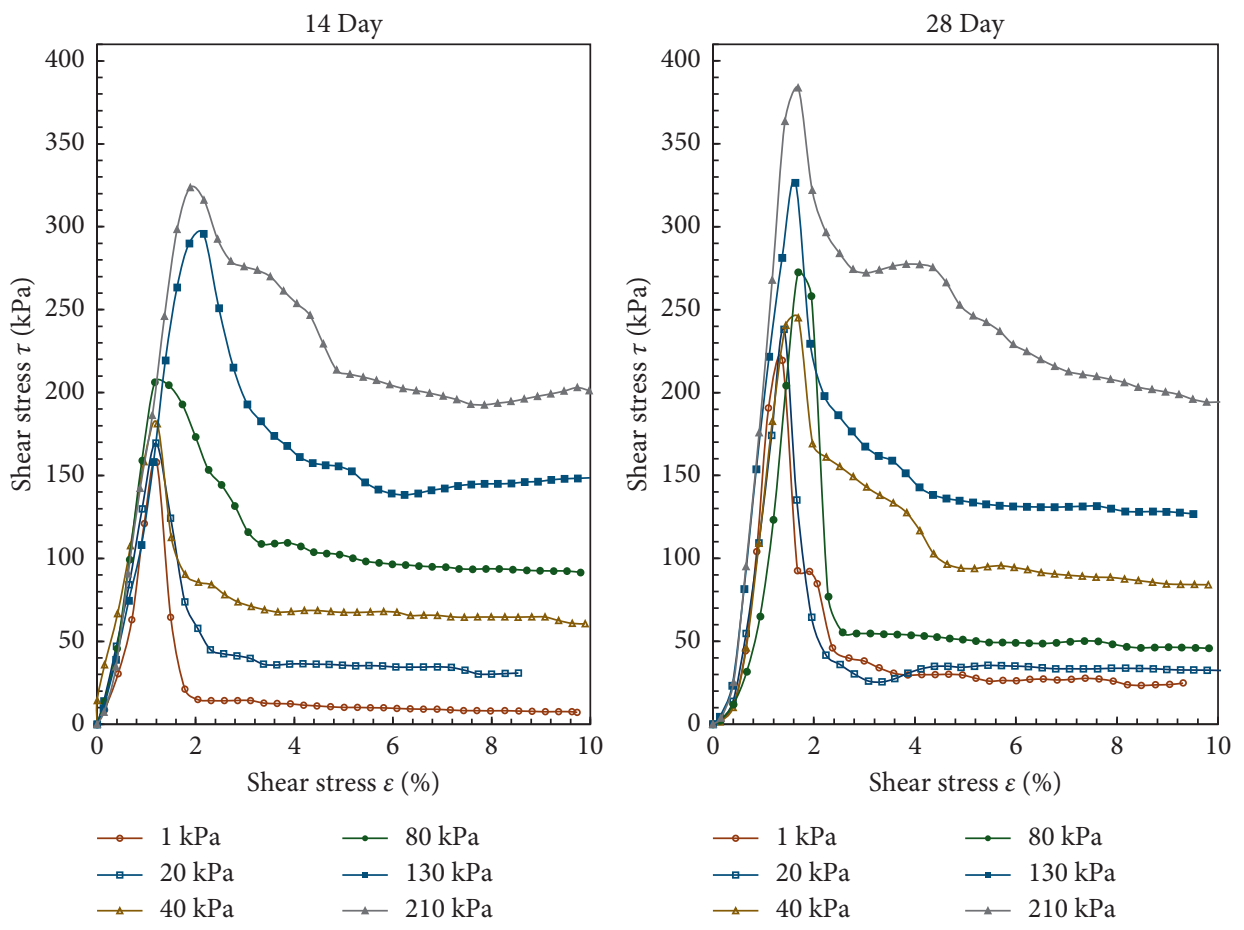

$$
\begin{aligned}
& \rightarrow 1 \mathrm{kPa} \quad \longrightarrow 80 \mathrm{kPa} \\
& \rightarrow 20 \mathrm{kPa} \quad \rightarrow 130 \mathrm{kPa} \\
& \rightarrow 40 \mathrm{kPa} \longrightarrow 210 \mathrm{kPa}
\end{aligned}
$$

Figure 10: Shear stress-strain curve of $9.7 \%$ CPB. 


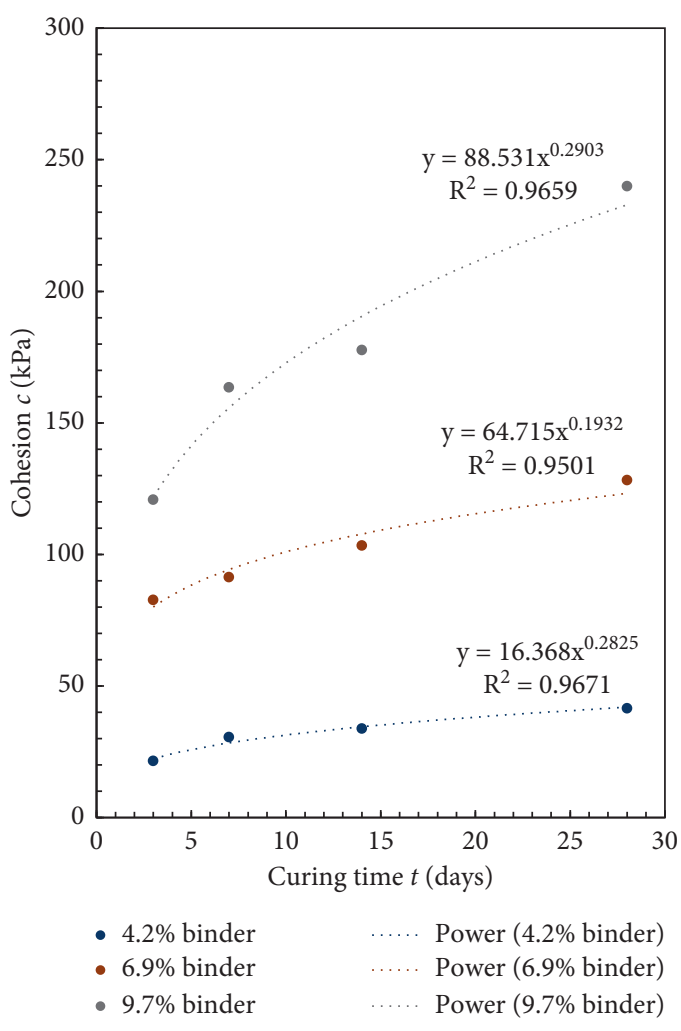

(a)

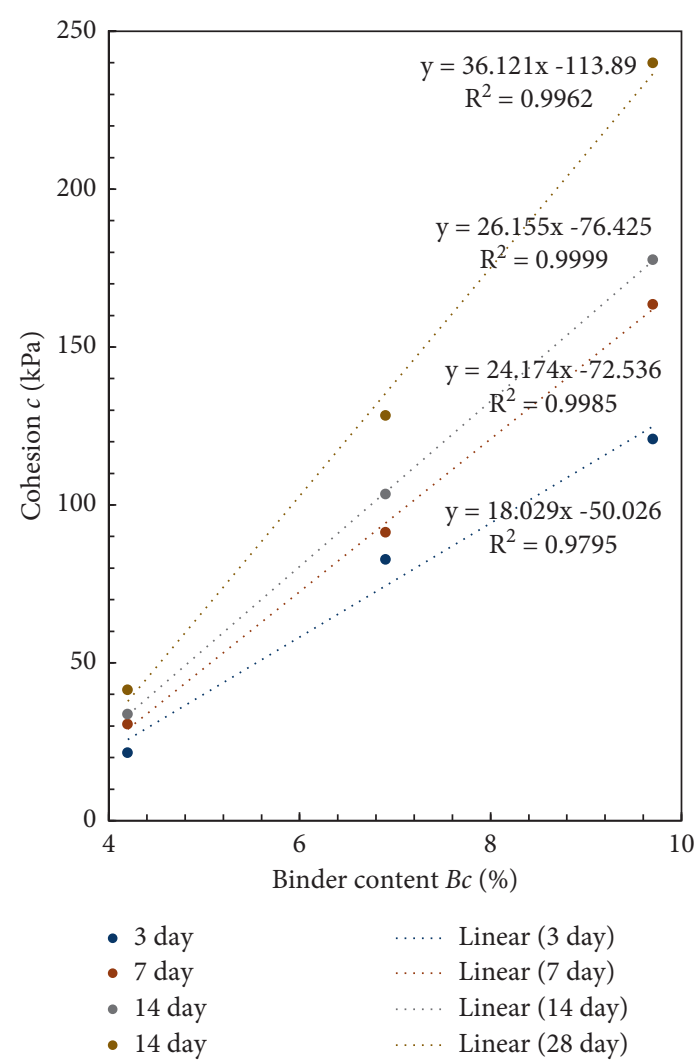

(b)

Figure 11: Shear strength with curing time and binder content.

\section{Conclusions}

This paper presents the results of an experimental investigation of the shear properties of CPB under low confining stress. Based on the obtained results, the following conclusions can be drawn:

(i) The strength envelope shows the strength behavior is governed by binder contents and curing time. CPB follows the Mohr-Coulomb envelope with the peak strength being controlled by cohesion and the angle of frictional resistance, while the residual strength is controlled by the angle of frictional resistance alone. This can be explained in that the cohesion is controlled by the cement bond, and the increase in cohesion is proportional to the binder contents and curing time. This finding means that binder contents and curing time have a significant impact on the shear property of $\mathrm{CPB}$.

(ii) The stress-strain results show that the postfailure behavior is controlled by the frictional resistance which can be generalized into strain softening or strain hardening based on the confining stress. Under high binder contents, the softening behavior is characterized by an elastic perfectly plastic curve with an instantaneous drop in shear strength following the failure. Under low binder contents, the strain hardening behavior is characterized by ductile behavior with a continuous strength increase. The stress-strain curve shows that shear modulus is more related to the binder content than the curing time, which trend is observed in all the trials of $4.2 \%, 6.9 \%$, and $9.7 \% \mathrm{CPB}$. This can be attributed to a higher cementation binding force between $\mathrm{CPB}$ resulting in a higher degree of binder hydration.

It should be noted that this research presents the values of shear strength, cohesion, and friction angle of CPB for a maximum of 28 days of curing time. The values are useful for numerical modeling and CPB behavior in the short term. However, the parameters in the long term are not determined in this study. The mechanical behavior of the CPB changes as a function of time due to the heterogeneity of mine tailings. The research in this area is not implemented in the project for this study; it could be performed in future studies. The results in this research may help to understand the mechanical behavior of the $\mathrm{CPB}$ in general and, in particular, analyze shear strength with binder contents and curing time that is crucially important in underground mine stability.

\section{Data Availability}

All data, models, or codes that support the findings of this study are available from the corresponding author upon reasonable request. 


\section{Disclosure}

The funders had no role in the design of the study, in the collection, analyses, or interpretation of data, in the writing of the manuscript, or in the decision to publish the results.

\section{Conflicts of Interest}

The authors declare no conflicts of interest.

\section{Acknowledgments}

The authors would like to acknowledge the Williams Operation for providing tailings, binders, and process water. They would also like to thank Dr. Mohammadamin Jafari, Department of Civil and Mineral Engineering at the University of Toronto, for his technical support. This study was funded by the National Science and Engineering Research Council (NSERC) of Canada, University of Toronto, State Key Research Development Program of China, and the industrial funding from the Barrick Gold Corporation.

\section{References}

[1] Paterson \& Cooke Canada, Mine Backfill Design \& Operation Course, Patterson \& Cooke, Sudbury, Canada, 2019.

[2] F. Hassani and J. Archibald, Mine Backfill, Canadian Institute of Mining, Metallurgy and Petroleum, Montreal, Canada, 1998.

[3] M. W. F. Grabinsky, "In situ monitoring for ground truthing paste backfill designs," in Proceedings of the 13th International Seminar on Paste and Thickened Tailings, pp. 85-98, Australian Centre for Geomechanics, Toronto, Canada, May 2010.

[4] C. Qi, Q. Chen, A. Fourie et al., "Constitutive modelling of cemented paste backfill: a data-mining approach," Construction and Building Materials, vol. 197, pp. 262-270, 2019.

[5] G. Liu, L. Guo, L. Li, and A. N. Pan, "Required strength evaluation model and its application for vertically exposed backfill: inspired by Mitchell's physical model tests," in Proceedings of the 22nd International Conference on Paste, Thickened and Filtered Tailings, Cape Town, South Africa, May 2019.

[6] J. Li, E. Yilmaz, and S. Cao, "Influence of solid content, cement/tailings ratio, and curing time on rheology and strength of cemented tailings backfill," Minerals, vol. 10, no. 10, p. 922, 2020.

[7] T. Zhang, H. Jin, L. Guo, W. Li, A. N. Pan, and D. Zhang, "Mechanism of alkali-activated copper-nickel slag material," Advances in Civil Engineering, vol. 2020, Article ID 7615848, 10 pages, 2020.

[8] R. J. Mitchell, R. S. Olsen, and J. D. Smith, "Model studies on cemented tailings used in mine backfill," Canadian Geotechnical Journal, vol. 19, no. 1, pp. 14-28, 1982.

[9] M. W. F. Grabinsky and A. N. Pan, "Cemented paste backfill failure envelope at low confining stress," in Proceedings of the the 13th International Symposium on Mining with Backfill, Katowice, Poland, May 2021.

[10] R. L. Veenstra, "A design procedure for determining the in situ stresses of early age cemented paste backfill," Ph.D. thesis, University of Toronto, Toronto, Canada, 2013.

[11] N. J. F. Koupouli, T. Belem, P. Rivard, and H. Effenguet, "Direct shear tests on cemented paste backfill-rock wall and cemented paste backfill-backfill interfaces," Journal of rock mechanics and geotechnical engineering, vol. 8, no. 4, pp. 472-479, 2016.

[12] O. Nasir and M. Fall, "Shear behaviour of cemented pastefillrock interfaces," Engineering Geology, vol. 101, no. 3-4, pp. 146-153, 2008.

[13] A. Kesimal, E. Yilmaz, B. Ercikdi, I. Alp, and H. Deveci, "Effect of properties of tailings and binder on the short-and longterm strength and stability of cemented paste backfill," $M a$ terials Letters, vol. 59, no. 28, pp. 3703-3709, 2005.

[14] A. Pan and M. Grabinsky, "Tensile strength of cemented paste backfill," Geotechnical Testing Journal, vol. 44, 2021.

[15] A. Marston, "The theory of external loads on closed conduits in the light of latest," Bulletin, vol. 96, 1930.

[16] B. D. Thompson, W. F. Bawden, and M. W. Grabinsky, "In situ measurements of cemented paste backfill at the Cayeli mine," Canadian Geotechnical Journal, vol. 49, no. 7, pp. 755-772, 2012.

[17] W. Li, L. Guo, G. Liu, and A. N. Pan, "Analytical and experimental investigation of the relationship between spread and yield stress in the mini-cone test for cemented tailings backfill," Construction and Building Materials, vol. 260, pp. 1-8, 2020.

[18] Roscoe Postle Associates, Technical Report on the Hemlo Mine, Barrick Gold Corporation, Marathon, Canada, 2017.

[19] M. Jafari, M. Shahsavari, and M. W. F. Grabinsky, "Hydration effects on specific gravity and void ratio of cemented paste backfill," Geotechnical Testing Journal, vol. 43, no. 5, pp. 1300-1316, 2020.

[20] M. Jafari, M. Shahsavari, and M. Grabinsky, "Cemented paste backfill 1-D consolidation results interpreted in the context of ground reaction curves," Rock Mechanics and Rock Engineering, vol. 53, no. 9, pp. 4299-4308, 2020.

[21] ASTM Standard, D 3080: Standard Test Method for Direct Shear Test of Soils under Consolidated Drained Conditions, ASTM International, West Conshohocken, PA, USA, 2011. 